\title{
Which preparatory curriculum for the International Baccalaureate Diploma Programme is best? The challenge for international schools with regard to mathematics and science
}

\author{
M. Sencer Corlu
}

Published online: 1 November 2014

(C) Springer Science+Business Media Dordrecht and UNESCO Institute for Lifelong Learning 2014

\begin{abstract}
There are two mainstream curricula for international school students at the junior high level: the International Baccalaureate (IB) Middle Years Programme (MYP) and the Cambridge International General Certificate of Secondary Education (IGCSE). The former was developed in the mid-1990s and is currently being relaunched in a 21 st-century approach. The latter programme of study was developed by University of Cambridge International Examinations in 1985 and has become popular in recent years among British domestic and international schools worldwide due to the clarity of its learning content. The prevailing uncertainty about which curriculum is best to prepare students for the IB Diploma Programme represents a challenge for international schools. The purpose of the current study is to develop a methodology through causal models which can explain the relationship between student performance in the IGCSE and the Diploma Programme with regard to mathematics and science. The data evaluated here consisted of external examination scores of students who attended a private international high school between the years 2005 and 2012. Two structural equation models were developed. The first model employed a maximum likelihood estimation, while the second model used a Bayesian estimation with a Markov Chain Monte Carlo method. Both models fit the data well. The evidence suggests that the IGCSE provides a good foundational preparation for the Diploma Programme in mathematics and science.
\end{abstract}

Keywords International schools $\cdot$ Middle Years Programme (MYP) - International General Certificate of Secondary Education (IGCSE) - Diploma Programme (DP) · Mathematics education - Science education - Structural equation modelling

Résumé Quel programme préparatoire au diplôme du baccalauréat international est le meilleur ? Le défi des écoles internationales avec les mathématiques et les

M. S. Corlu ( $\square)$

Graduate School of Education, Bilkent University, 06800 Bilkent, Ankara, Turkey

e-mail: sencer.corlu@bilkent.edu.tr 
sciences en exemple - Il existe deux programmes principaux pour les élèves du premier cycle de l'enseignement secondaire des écoles internationales : le Programme de premier cycle secondaire (PPCS) de l'Organisation du Baccalauréat International (IB) et le Certificat général de l'enseignement secondaire (Cambridge International General Certificate of Secondary Education, IGCSE). Le premier a été introduit au milieu des années 1990 et est actuellement remanié selon une approche adaptée au XXIe siècle. Créé en 1995 par l'unité des examens internationaux de l'université de Cambridge, le second programme d'études est prisé ces dernières années par les écoles britanniques nationales et internationales implantées à l'étranger, en raison de la clarté de ses contenus éducatifs. L'incertitude actuelle sur le meilleur programme pour préparer les élèves au baccalauréat international constitue un défi pour les écoles internationales. L'étude présentée ici poursuivait l'objectif d'élaborer une méthodologie au moyen de modèles de causalité, qui peuvent expliquer la relation entre les résultats des élèves en mathématiques et en sciences et chacun des deux cursus. Les données évaluées dans ce but consistent en les notes obtenues aux examens externes des élèves inscrits dans une école secondaire internationale privée durant les années 2005 à 2012. Deux modèles par équations structurelles ont été élaborés. Le premier a utilisé une estimation de probabilité maximale, le second une estimation bayésienne avec une méthode de Monte Carlo par chaîne de Markov. Les deux modèles ont présenté une bonne adéquation des données. Les conclusions suggèrent que l'IGCSE fournit une bonne préparation de base en mathématiques et en sciences pour le programme du diplôme.

\section{Introduction}

International schools are historically characterised by a liberal and humanist culture, educating highly mobile students for a globalised world (Walker 2000). On the one hand, this liberal and humanist culture is supported by an idealistic perspective, which aims to build up a mutual understanding among individuals with diverse cultural and social backgrounds through communication and independent inquiry. On the other hand, the pragmatic needs of highly mobile students necessitate an education which is recognised internationally or in their home countries. However, the purposes, practices and outcomes of international schools are too complex to be explained with a dichotomy of idealistic or pragmatic views (Bates 2011; Cambridge and Thompson 2004). Several other cultural and ideological factors are likely to influence important decisions taken within international school contexts, and those factors can be volatile partly due to the dynamic and everchanging composition of students, parents, teachers or other decision makers.

One of the most challenging issues which decision makers at international schools need to resolve is what kind of knowledge they believe is of most worth. This issue is directly related to the choice of the curriculum, since their decision shapes what is taught and in which cultural and ideological context it is taught. Moreover, the dynamic environment of international schools demands other decisions to be taken, including curricular coherence, consistency and continuity. 
These decisions are critical, particularly for international schools which design their own curricula or mix a variety of national and international curricula in order to meet the needs of their students (Stobie 2005).

Many international schools prefer to adopt either the Middle Years Programme (MYP) or the International General Certificate of Secondary Education (IGCSE) at junior high level (9th and 10th grades). This choice depends on their belief regarding which one will provide students with the most solid preparation for the International Baccalaureate Diploma Programme (DP) at the senior level (11th and 12th grades) (Guy 2000). This preparation should not be limited to helping students succeed in the formal DP examinations, because DP in fact also requires students to develop independent inquiry and community awareness skills. The extended essay is one example of an in-depth study which offers the opportunity for students to engage in subject-specific independent inquiry of a topic of interest (IB 2013).

The prevailing uncertainty about which DP preparatory curriculum is the best creates a challenge for international schools. Research indicates that some international schools prefer MYP because they believe that MYP builds on the foundational knowledge and skills necessary for students to be successful in DP (Reimers 2004). Those with a pro-MYP view emphasise that the process-based and holistic nature of MYP means it provides international students with an educational continuum from 6th to 10th grades which is internally assessed by their own teachers (Ellwood 1999). In fact, some support MYP with an idealistic belief that the programme has been instrumental in fostering international-mindedness through its cross-curricular themes (Stobie 2005).

IGCSE was developed for, and has traditionally been implemented in, British overseas schools, as a two-year programme for 10th and 11th grades of individual (differentiated) subjects undertaken in preparation for externally assessed formal examinations. The IGCSE programme of study has gained popularity in recent years among international schools due to the clarity of its learning content (NashmanSmith and Taylor 2004; Richardson 2010). Another reason behind the popularity of IGCSE can be found in the pragmatic need for a formal curriculum which offers external examinations (Hayden and Thompson 1998).

There is little empirical research to support the assertion that either MYP or IGCSE is a well-rounded DP-preparatory programme. There is even less research on the effect of IGCSE on student performance in DP. To be able to decide, international schools need evidence from research, which will also build a scholarly knowledge base in this area. The current note, with a focus on mathematics and science, is one of several subject-specific studies I am currently conducting with my colleagues and graduate students (see Corlu et al. 2014; Sagun and Corlu 2014). I believe that subject-specific empirical research has the potential to help international schools make informed decisions and choose the best curriculum for preparing their students for DP. The lack of an external examination in MYP suggests employing alternative methodologies for research, which is also warranted (see Stobie 2005). However, the purpose of the current study is limited to developing a methodology through causal models which can explain the relationship between student performance in IGCSE and in DP at a typical international school setting. 


\section{Methodology}

Our data consisted of external examination scores of high school students $(N=250$, 132 female), who attended a private international high school in a major city in Turkey between the years 2005 and 2012. Students were typical international students in the sense that they had high socioeconomic status (Dunne and Edwards 2010), and according to the school registrar's office, were mostly children of staff members at nearby universities or members of foreign diplomatic missions in the city. All participants were enrolled in DP mathematics and at least one science course and had been preparing for the IGCSE mathematics and science examinations while at this particular non-selective school.

The variables we measured were student scores in external examinations, including DP mathematics (dpmath), DP science (dpscience, composed of mean scores in physics, chemistry, and/or biology), IGCSE mathematics (imath), and IGCSE science (iscience), in addition to two variables indicating whether or not students had written an extended essay project in mathematics (eemath) and in science (eescience). The range of all external examination scores for both DP and IGCSE was from 1 to 7 (highest). Two latent variables were inferred: mathematics and science proficiency (DP exit level) and readiness for DP (IGCSE exit level). Latent variables did not represent data collected from the participants but were rather inferred from the regression model to represent the constructs (Kline 2005).

Data were first examined with respect to statistical assumptions underlying structural equation modelling. After observing that the statistical assumptions were met, two models were developed. Our first model employed a maximum likelihood estimation while the second model used a Bayesian estimation with a Markov Chain Monte Carlo method in order to include the ordered-categorical variables, eemath and eescience, into our framework (Arbuckle 2009). In the first model, several fit indices were consulted (Barrett 2007; Tabachnick and Fidell 2007). The second model provided an acceptable posterior predictive value. Statistically, both models were considered to reflect an acceptable fit to the data. Theoretically, the first model was a reflection of the pragmatic view by including only the exam scores in the analysis, while the second model broadened the analysis to the idealistic view by considering the extended essay choices of the students.

\section{Key findings}

Table 1 presents the means and standard deviations for participants' scores on IGCSE and DP examinations. When compared with mean scores of all DP students in the world, the participants in our sample did slightly better (IB 2012). This comparison procedure was conducted by using a one-sample $t$ test.

It is observed in the data that the strength of the relationship between IGCSE mathematics and science $\left(r=.79 ; r^{2}=.62\right)$ was slightly stronger than the strength of the relationship between DP mathematics and science $\left(r=.64 ; r^{2}=.41\right)$. When compared to previously conducted research on mathematics and science correlation, this finding was not noteworthy ( $\mathrm{Li}$ et al. 2002). See Table 2. 
Table 1 Descriptive statistics

\begin{tabular}{lll}
\hline & Mean & SD \\
\hline dpmath & 4.98 & 1.25 \\
dpscience & 4.45 & 1.28 \\
imath & 5.14 & 1.26 \\
iscience & 4.50 & 1.34 \\
\hline
\end{tabular}

Table 2 Bivariate correlations

\begin{tabular}{|c|c|c|c|c|c|c|}
\hline & dpscience & dpmath & imath & iscience & eemath & eescience \\
\hline dpscience & 1 & $.64^{*}$ & $.61 *$ & $.68 *$ & $.24 *$ & .09 \\
\hline dpmath & & 1 & $.54 *$ & $.53 *$ & $.13 *$ & .04 \\
\hline imath & & & 1 & $.79^{*}$ & .11 & $.16^{*}$ \\
\hline iscience & & & & 1 & $.20 *$ & $.21^{*}$ \\
\hline eemath & & & & & 1 & -.07 \\
\hline eescience & & & & & & 1 \\
\hline
\end{tabular}

* Correlation is statistically significant $(p<.05)$

Figure 1 presents a graphical representation of the first model, which was developed as a reflection of the pragmatic view in the sense that the model considered only the external examination scores. All standardised regression weights, shown by the arrows, were statistically significant. A major finding was the instrumental role of IGCSE in predicting students' proficiency levels in mathematics and science at the end of DP $(\beta=.82, p<.05)$. Thus, if students scored one standard deviation higher in IGCSE, their DP scores would increase by .82 standard deviations. This initial model explained 68 per cent of the variance in students' proficiency levels in mathematics and science at the end of DP.

The second model broadened the analysis to the idealistic view by including both the external examination scores and students' choices whether or not to write an extended essay. This model showed that students' mathematics and science proficiency had a larger effect on their decisions regarding whether to write an extended essay in mathematics $(\beta=.66)$ than their decision regarding whether to write an extended essay in science $(\beta=.22)$. See Fig. 2 . Thus, writing an inquirybased paper in mathematics seemed to make students believe that they needed an advanced subject-specific knowledge of mathematics. Students' beliefs about what would be expected of them did not seem to be as strong in science as was the case in mathematics.

\section{Discussion and conclusion}

Findings in the first model provide evidence that IGCSE has the potential to satisfy the needs of those international schools which adopt a merely pragmatic view of the DP. The strong relationship between IGCSE scores and students' subsequent 


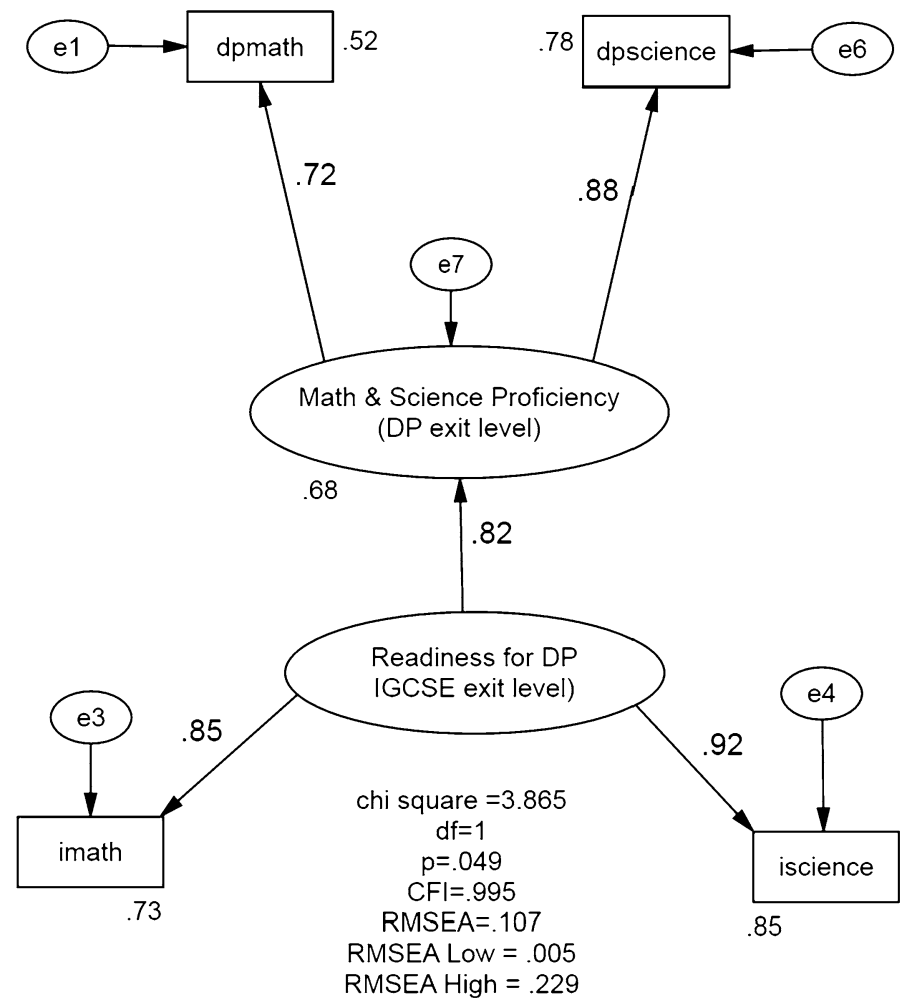

Fig. 1 First model of mathematics and science proficiency at DP exit level

success in DP examinations can be best explained as demonstrating students' need to "take examinations before they tackle the demands of the IB Diploma examinations in grade 12" (Nashman-Smith and Taylor 2004, p. 19). Developing test-taking skills or learning how to cope with stress during their IGCSE programme may help students be better prepared towards DP examinations (Suldo and Shaunessy-Dedrick 2013). In addition, previous research suggests that external examinations are likely to encourage schools to schedule extra hours of mathematics and science instruction (Bishop 1995) or recruit teachers with substantial experience in preparing students to the test (Garton 2000; Hayden 2006). This pragmatic support for IGCSE is grounded in research showing that external examination systems have a pervasive effect on students, teachers and school administrators.

When the pragmatic and idealistic views were considered concurrently in the second model, findings showed a stronger support for IGCSE in mathematics than for science. The IGCSE-DP continuity seems to help students understand that they need strong subject-matter knowledge in order to conduct inquiry in mathematics. However, it may be speculated that the IGCSE-DP continuum is inadequate to help students realise the connection between theory and practice; thus they do not necessarily understand that conducting an independent inquiry in science requires skills beyond basic scientific literacy (Corlu and Corlu 2012). The emphasis on 


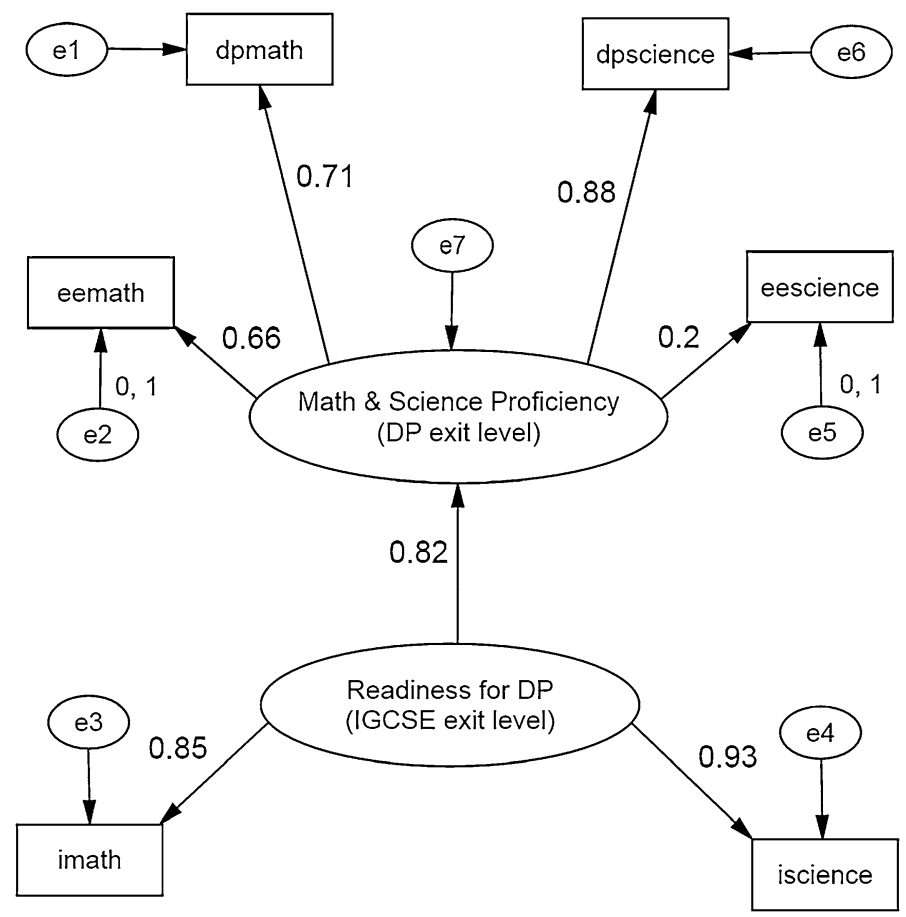

Fig. 2 Second model with extended essay choices

practical work is evident in both curricula (Cambridge International Examinations 2013; IB 2011), however, it is advised that teachers provide students with opportunities to handle scientific equipment independently during their extended essay projects and ensure that strong subject-matter knowledge is evident prior to undertaking the responsibility of conducting an independent inquiry in science (Hofstein and Lunetta 2003). Otherwise, it may not be possible for students to construct knowledge independently and appreciate the environmental, social or ethical implications of science.

As a former teacher of MYP, IGCSE and DP, I see the merits of all three systems and do not claim that IGCSE offers better preparation for DP than MYP does. Neither does my research make any such claim. However, I believe in the necessity of external examinations to increase student and teacher performance, and in rigorous tasks within the curriculum which would help students appreciate the multiplicity of science and mathematics as human endeavours.

\section{References}

Arbuckle, J. L. (2009). Amos 18 user's guide. Crawfordville, FL: Amos Development Corporation. Barrett, P. (2007). Structural equation modelling: Adjudging model fit. Personality and Individual Differences, 42(5), 815-824. 
Bates, R. (2011). Schooling internationally: Globalisation, internationalisation and the future for international schools. London: Routledge.

Bishop, J. H. (1995). The impact of curriculum-based external examinations on school priorities and student learning (CAHRS Working Paper \#95-30). Ithaca, NY: Cornell University.

Cambridge International Examinations (2013). Cambridge IGCSE. Accessed September 22, 2014, from http://www.cie.org.uk/programmes-and-qualifications/cambridge-secondary-2/cambridge-igcse.

Cambridge, J., \& Thompson, J. (2004). Internationalism and globalization as contexts for international education. Compare: A Journal of Comparative Education, 34(2), 161-175.

Corlu, M. A., \& Corlu, M. S. (2012). Scientific inquiry based professional development models in teacher education. Educational Sciences: Theory \& Practice, 12(1), 514-521.

Corlu, M. S., Sagun, S., Yağız, B., Niğdelioğlu, R. M., Dulun, Ö., Özcan, T. \& Ateşkan, A. (2014). Fen bilimleri ve matematik ĕgitimine küresel bir baklş: Uluslararast ĕgitim program ve prensiplerinin Türkiye ölçeğinde de ğerlendirilmesi [A global perspective to science and mathematics education: An evaluation of the international education programs in the Turkish context]. Paper presented at the XI. Ulusal Fen Bilimleri ve Matematik Kongresi, Adana, Turkey.

Dunne, S., \& Edwards, J. (2010). International schools as sites of social change. Journal of Research in International Education, 9(1), 24-39.

Ellwood, C. (1999). IGCSE and IB Middle Years Programme: How compatible are they? International Schools Journal, 19(1), 35-44.

Garton, B. (2000). Recruitment of teachers for international education. In M. Hayden \& J. Thompson (Eds.), International schools and international education: Improving teaching, management and quality (pp. 85-95). London: Kogan Page.

Guy, J. (2000). IBMYP and IGCSE: Are they really compatible? A response to Caroline Ellwood. Part I. International Schools Journal, 20(1), 10-17.

Hayden, M. C. (2006). Introduction to international education: International schools and their communities. London: Sage.

Hayden, M. C., \& Thompson, J. J. (1998). International education: Perceptions of teachers in international schools. International Review of Education, 44(5/6), 549-568.

Hofstein, A., \& Lunetta, V. N. (2003). The laboratory in science education: Foundations for the twentyfirst century. Science Education, 88(1), 28-54.

IB (International Baccalaureate). (2011). Science across the IB continuum. Cardiff, Wales: International Baccalaureate.

IB (International Baccalaureate). (2012). The IB Diploma Programme statistical bulletin. Den Haag, Netherlands: International Baccalaureate.

IB (International Baccalaureate). (2013). Extended essay guide: First exams 2013. Cardiff: International Baccalaureate.

Kline, R. B. (2005). Principles and practice of structural equation modeling. New York: Guilford Press.

Li, M., Shavelson, R. J., Kupermintz, H., \& Ruiz-Primo, M. A. (2002). On the relationship between mathematics and science achievement in the United States. In D. F. Robitalle \& A. E. Beaton (Eds.), Secondary analysis of the TIMSS Data (pp. 233-249). Dordrecht: Kluwer.

Nashman-Smith, M., \& Taylor, R. (2004). Integrating the IB MYP and IGCSE. International Schools Journal, 24(1), 19-25.

Reimers, C. (2004). From MYP to diploma: An investigation of the impact of the Middle Years Programme on International Baccalaureate Diploma candidates. International Schools Journal, 24(2), 11-18.

Richardson, H. (2010). Academies “want to teach IGCSEs”. Accessed 5 September 2014 from http://bbc. co.uk.

Sagun, S., \& Corlu, M. S. (2014). Resolving the dilemma of international school curriculum: The case of biology. Eurasia Journal of Mathematics, Science, and Technology Education, 10(2), 153-158.

Stobie, T. (2005). To what extent do the Middle Years Programme and Diploma Programme of the International Baccalaureate Organization provide a coherent and consistent educational continuum? International School Journal, 25(1), 30-40.

Suldo, S. M., \& Shaunessy-Dedrick, E. (2013). The psychosocial functioning of high school students in academically rigorous programs. Psychology in the Schools, 50(8), 823-843.

Tabachnick, G. G., \& Fidell, L. S. (2007). Experimental designs using ANOVA. Belmont, CA: Duxbury. Walker, G. R. (2000). One-way streets of our culture. International Schools Journal, 19(2), 11-19. 


\section{The author}

M. Sencer Corlu is an assistant professor at the Graduate School of Education of Bilkent University. He has several years of experience in implementing mathematics and science at international schools in Morocco, Switzerland and Turkey. 